\title{
The evolutionary origin of protein complexes Jose Pereira-Leal*
}

Address: Medical Research Council, Laboratory of Molecular Biology, Cambridge University, UK.

Email: Jose Pereira-Leal* - jleal@mrc-lmb.cam.ac.uk

* Corresponding author

from BioSysBio: Bioinformatics and Systems Biology Conference

Edinburgh, UK, I4-15 July 2005

Published: 2I September 2005

BMC Bioinformatics 2005, 6(Suppl 3):S3

Cellular networks are organized into functional modules that accomplish discrete biological processes. The evolutionary mechanisms driving the emergence of this modular character are still unclear. Protein complexes are functional modules in protein interaction networks, suitable to study the origins of modularity. I'll discuss how gene duplication of a specific set of genes is associated with the emergence of protein complexes in evolution. Theoretical modeling and data analyses point to the duplication of genes coding for proteins capable of forming self interactions (homomeric interactions) being central in the origins of protein complexes. I'll discuss the different structural and functional consequences of such duplications. 